\title{
16
}

\section{The Religious Problems and the Theory of Being}

In the literature of Natural Religion at least three different conceptions of the subject are represented. The first of these conceptions regards Natural Religion as a search for what a well-known phrase has called "the way through Nature to God." If we accept this conception, we begin by recognizing both the existence of the physical world and the validity of the ordinary methods and conceptions of the special sciences of nature. We undertake to investigate what light, if any, the broader generalizations of natural science, when once accepted as statements about external reality, throw upon the problems of religion. It belongs, for instance, to this sort of inquiry to ask: What countenance does the present state of science give to the traditional argument from Design?

The second of our three conceptions views Religion less as a doctrine to be proved or disproved through a study of the external world than as a kind of consciousness whose justification lies in its rank amongst the various inner manifestations of our human nature. Man, so this conception holds, is essentially a religious being. He has religion because his own inmost nature craves it. If you wish, then, to justify religion, or even to comprehend it, you must view it, not as a theory to be proved or disproved by an appeal to external reality, but rather as a faith to be estimated through reference to the

[Reprinted from $W 1, \mathrm{r}: 3-43$. 
inner consciousness of those who need, who create, and who enjoy religion. From this point of view the study of Natural Religion concerns itself less with proof than with confession, with a taxing of interior values, and with a description of the religious experience of mankind. A somewhat extended interpretation of this point of view treats the purely historical study of the various religions of mankind as a contribution to our comprehension of Natural Religion.

But a third conception of the study of Natural Religion remains. This third view identifies the doctrine in question with the fundamental Philosophy of Religion. It is the Nature of Things, viewed in the light of the most critical examination of our reason, that is now the object of an inquiry into Natural Religion. The problems at issue are, for this view, those of Aristotle's Metaphysics, of Fichte's Wissenschaftslebre, of Hegel's Logik,-of all the undertakings that, in the history of thought, have most directly attempted the contemplation of Being as Being. For our first conception the student of Natural Religion, having accepted the natural knowledge of his time as valid, and not having attempted to delve beneath the foundations of that knowledge, seeks to interpret external nature in the light of religious interests. For our second conception Natural Religion is viewed simply as the voice of human nature itself, whose faith is to be expressed, whose ideals are to be recorded, whose will and whose needs are to be, above all, consulted and portrayed, since, for this view, the consciousness of those who believe in religious truth is, when once made articulate, its own apology. But, for our third conception, the office of the student of Natural Religion is to deal with the most fundamental metaphysical problems. He is for this view a thorough-going critic of the foundations of our faith, and of the means of our insight into the true nature of Reality.

All these three conceptions, however much they may differ, have in common what makes it proper enough to view them as conceptions of the study of Natural Religion. For they are all three concerned with religion; they can all alike be pursued without explicit dependence upon any creed as to a revealed religion; and finally, they are busied about some relation between the natural order of truth and the contents of religious doctrine. They differ in the sort of natural truth that forms their starting-point, or that limits the scope of the invesigation which they propose. I suppose that no one of these various lines of inquiry will ever come to be wholly ne- 
glected. But their office is distinct. And I mention them here in order all the more clearly to say, at the outset, that our own business, in these lectures, is with the most neglected and arduous of the methods of studying the relations between religion and the ultimate problems of the Theory of Being. From the first, to be sure, we shall be concerned, in one sense, with human nature, as every philosophy has to be concerned. And in the latter half of this course the Philosophy of Nature will play a part in our investigation. But the central problem of our discussion will be the question: What is Reality?

\section{I}

In thus stating, in the opening words, the plan of these lectures, I do so with a full sense of the shadow that such a programme may, at the first glimpse, seem to cast upon the prospects of our whole undertaking. It is true that, in calling the fundamental problems of the Metaphysic of Religion relatively neglected, I do not fail to recognize that they are both ancient and celebrated, and that some of us may think them even hackneyed. It is certainly not uncommon to call them antiquated. But what I have meant by the phrase "relatively neglected" is that, compared with the more easily accessible fashions of dealing with Natural Religion, the strictly metaphysical treatment less frequently involves that sort of ardent hand-to-hand struggle with the genuine issues themselves that goes on when men are hopefully interested in a study for its own sake. It is one thing to expound, or even to assail, the theology of Hegel or of St. Thomas, or to report any of those various quaint opinions of philosophers in which even the popular mind often delights. It is another thing to grapple with the issues of life for one's self. The wiser religions have always told us that we cannot be saved through the piety of our neighbors, but have to work out our own salvation with fear and trembling. Well, just so the theoretical student of Natural Religion has to learn that he cannot comprehend ultimate philosophical truth merely by reading the reports of other people's reasonings, but must do his thinking for himself, not indeed without due instruction, but certainly without depending wholly upon his text-books. And if this be true, then the final issues of religious philosophy may be said to be relatively neglected, so long as students are not constantly afresh grappling with the ancient problems, and giving them renderings 
due to direct personal contact with their intricacies. It is not a question of any needed originality of opinion, but it is rather a matter of our individual intimacy with these issues.

And now, in recognizing the fact of the comparative neglect of the Theory of Being in the discussions of Natural Religion, I recognize also the motives that tend to make such an inquiry seem, at the first glimpse, unpromising. These motives may be expressed in the forms of three objections, namely, first, that such undertakings are pretentious, by reason of the dignity and the mystery of the topic; secondly, that they are dreary, by reason of the subtle distinctions and the airy abstractions involved in every such research; and thirdly, that they are opposed, in spirit, to the sort of study for which in our day the sciences of experience have given the only worthy model.

Such objections are as inevitable as they are, to lovers of philosophy, harmless. Philosophy necessarily involves a good deal of courage; but so does life in general. It is pretentious to wrestle with angels; but there are some blessings that you cannot win in any other way. Philosophy is an old affair in human history; but that does not make the effort at individuality in one's fashion of thinking a less worthy ideal for every new mind. As to the dreariness of metaphysics, it is always the case, both in religion, and in thinking about religion, that, just as the letter killeth, and the spirit giveth life, so the mere report of tradition is dreary, but the inward life of thinking for one's self the meaning within or behind the tradition constitutes the very coming of the Spirit of Truth himself into our own spirits; and that coming of the Spirit, in so far as it occurs at all, never seems to any of us dreary. As for the fine-drawn distinctions and airy abstractions, no distinction is ever too subtle for you, at the moment when it occurs to you to make that distinction for yourself, and not merely to hear that somebody else has made it. And no abstraction seems to you too airy in the hour when you rise upon your own wings to the region where just that abstraction happens to be an element in the concrete fulness of your thoughtful life. Now it chances to be a truth of metaphysics, as it is an experience of religion, that just when you are most individual, most alone, as it were, in your personal thinking, about ultimate and divine matters, you are most completely one with that universal Spirit of Truth of which we just spoke. It is then your personal process of thinking that both gives interest to the subject and secures your relation to the Reality. Hence not the universality nor yet the ultimate character of the 
principles of which we think, but rather our own sluggishness in thinking, is responsible for the supposed dreariness of the Theory of Being. As Aristotle observed, that Theory itself is what all men most desire. You may in these regions either think or not think the truth; but you cannot think the truth without loving it; and the dreariness which men often impute to Metaphysics, is merely the dreariness of not understanding the subject,-a sort of dreariness for which indeed there is no help except learning to understand. In fact, nobody can ever regret seeing ultimate truth. That we shall hereafter find to be, so to speak, one of the immediate implications of our very definition of Being. When people complain of philosophy as a dreary enterprise, they are then merely complaining of their own lack of philosophical insight. The lover of philosophy can only offer them his sincerest agreement, and sympathy, so far as concerns the ground of their own complaint. He too shares their complaint, for he is human, and finds his own unwisdom dreary. But he is at least looking lovingly toward yonder shining light, while they walk wearily with their backs to the Celestial City.

As to the supposed opposition between the methods of philosophy and those of the special sciences of experience,-it exists, but it does not mean any real opposition of spirit. Here are two ways of getting insight, not two opposed creeds. The very wealth and the growth of modern empirical research furnish especially strong reasons for supposing that the time is near when the central problems of the Theory of Being shall be ready for restatement. Our life does not grow long and healthily in one region, without being ready for new growth in other regions. The indirect influence of special science upon philosophy is sure, but does not always mean a logical dependence of philosophy upon the empirical results of science. Just so, pure mathematical science has no logical dependence upon physics. Yet we have all heard how largely physical science has influenced the lines of investigation followed by the modern mathematicians. Within the mathematical realm itself, pure Algebra, when once abstractly defined, is not logically dependent upon Geometry for its principles or for its theories, yet some theories of modern Algebra have actually developed largely under the spell, as it were, of ideas of an unquestionable geometrical origin. Now a similar relation, I think, will in future find the development of pure Philosophy, and in particular of Rational Theology, to the progress of the special sciences, both mathematical and empirical. I do not think it right to regard 
philosophy merely as a compendium of the results of special science. Philosophy has its own field. But on the other hand, to reflect upon the meaning of life and of science (and in such thorough-going Reflection philosophy consists), is a process whose seriousness and wealth must grow as our human life and science progress. And hence every great new advance of science demands a fresh consideration of philosophic issues, and will insure in the end a power to grasp, more critically and more deeply, the central problem of Being itself. Hence the more we possess of special science, the more hope we ought to have for pure Philosophy.

\section{II}

So much then for the most general definition and justification of the proposed scope of these lectures. I cannot forbear to point out the easily recognizable fact that, in thus defining the plan before us, I have merely tried to adhere, so far as I can, to the programme explicitly laid down by Lord Gifford. A study of religion is required of your lecturer, and Lord Gifford, as appears from the words of his Will, would himself have thought, above all, of studying religion not only as a matter of purely natural and rational knowledge, but primarily as a body of Ontological problems and opinions, in other words as, in its theory, a branch of the Theory of Being. It is of "God, the only Substance," that your lecturer, if his Ontology so far agrees with Lord Gifford's, will principally speak. Well then, I can best work in the spirit of Lord Gifford's requirements if I explicitly devote our principal attention to the ultimate problems of Ontology, laying due stress upon their relations to Religion.

And now let me venture to sketch, in outline, the particular discussions by which I propose to contribute my fragment towards a study of the inexhaustible problems propounded by Lord Gifford's Will. Programmes in philosophy, as Hegel used to say, mean far less than in other enterprises. But even here some sort of programme is needed to fix in advance our attention.

My precise undertaking then, in the following lectures, is to show what we mean by Being in general, and by the special sorts of Reality that we attribute to God, to the World, and to the Human Individual. These I regard as the problems of the ontology of religion. In every step of this undertaking I shall actually be, in a psychological and in an historical sense, dependent, both for my ideas and for 
their organization, upon this or that philosophical or theological tradition (well known to every student of philosophy); and therefore I must early introduce into my work a sketch of certain philosophical traditions in which we are to be especially interested. Here, of course, you might expect to find, as such an historical introduction to the later critical enterprises, either a summary of the history of the principal religious ideas, or some account of the technical history of the Philosophy of Religion itself. Yet for neither of these two very natural enterprises shall I have time. My very fragmentary historical discussions will be limited to an attempt to depict some of the principal conceptions concerning the ultimate nature of Being, in other words to sketch the history of what one might call the ontological predicate of the expression to be, or to be real, used as a means of asserting that something exists. I shall dwell upon the nature of Being, because to assert that God is, or that the World is, or even, with Descartes, that I am, implies that one knows what it is to be, or in other words, what the so-called existential predicate itself involves. Now it is true that the existential predicate, the word is used to assert the real Being of any object, is often viewed as something of an absolutely simple, ultimate, and indescribable meaning. Yet even if this view were sound, the ultimate and the simple are, in philosophy, as truly and as much topics for reflective study as are the most complex and derived ideas of our minds. Moreover, a great deal of popular religion seems to involve the notion that it is both easier and more important to know that God is, than to know, with any sort of articulation, What God is, so that if you express even a total ignorance of the Divine nature and attribute, there are some very traditionally minded people who will hardly dare to disagree with you, while if you express the least doubt of the assertion that God is, the same people will at once view you with horror as an atheist. Now this preference in much popular religious thinking for the ontological predicate in its purity is not an altogether rational preference. Yet we shall find that it is based upon very deep and even very worthy, if vague, instincts. It is true that if I pretend to know no attributes whatever, characterizing a given object $\mathrm{X}$, I seem to have won very little by believing that $\mathrm{X}$ nevertheless exists. Yet the fondness for the Unknowable in theology has been to some extent supported by the dim feeling that even in asserting the bare existence of a being, and especially of God, I am already committed to extremely important attributes, whose definition, even if not yet overt, 
is already, however darkly, implied in my abstract statement. It is interesting, therefore, to study historically what men have supposed themselves to mean by the ontological predicate.

The basis having been thus laid in the history of the subject, our lectures, at various points in the historical summary, will have at some length to undertake a critical comparison and analysis of the various meanings of the ontological predicate. Such an analysis will constantly show us unexpected connections of these meanings with the concrete interests of religion. We shall find it with ontology, as it certainly is with ethics. People often regard moral philosophy as a topic very abstract and dry. And yet wherever two or three are gathered together indulging in gossip about the doings of their neighbors, their speech, even if it involves out-and-out scandal, is devoted to a more or less critical discussion, to an illustration, and even to a sort of analysis of what are really very deep ethical problems,problems about what men ought to do, and about the intricate relations between law and passion in human life. Well, as even the most frivolous or scandalous gossip really manifests an intense, if rude concern, for the primal questions of moral philosophy, so our children and all our most simple and devout souls constantly talk ontology, discourse of being, face the central issues of reality, but know it not. Yet once face the true connection of abstract theory and daily life, and then one easily sees that life means theory, and that you deal constantly, and decisively, with the problems of the Theory of Being whenever you utter a serious word. This then is the reason why our ontological studies will bear directly upon the daily concerns of religion.

Our discussion of the general meaning and of the relative value of the various ontological predicates will, moreover, throw light, as we go, upon some of the best known of the special issues of the history of theology. We shall see, for instance, what has been the real motive that has made the doctrine of the speculative Mystics so important a factor in the life of the more complex religious faiths. We shall see too, in the great historical conflicts between the Realistic and the Mystical conceptions of the nature of Reality, the source of some of the most important controversies concerning the being and attributes of God, the existence of the physical world, and the nature of human individuality. Thus we shall gradually approach a position where we shall learn the inevitableness of a certain final conception of the meaning of our ontological predicates; and the result 
of our critical study will be a light that we may not wholly have anticipated, both upon the conception of God, and upon our notion of the relations between God, the World, and the Human Individual. With the development of these fundamental conceptions, the first of my two series of lectures will close. We shall herewith have stated the bases of religion.

The second series I intend first to devote to the application of our fundamental conceptions to the more special problems of the nature of the human Ego, the meaning of the finite realm called the Physical World, and the interpretation of Evolution. The vast extent of the discussions thus suggested will be limited, in our own case, by the very fact that we shall here be attempting merely the application of a single very general ontological idea to a few problems which we shall view rather as illustrations of our central thesis concerning Reality, than as matters to be exhaustively considered for their own sake. Having thus sketched our Cosmology, if I may call it such, we shall then conclude the whole undertaking by a summary discussion of the problems of Good and Evil, of Freedom, of Immortality, and of the destiny of the Individual, still reviewing our problems in the light of our general conception of Being. The title that I shall have given to the whole course of lectures, "The World and the Individual" will thus, I hope, prove to be justified by the scope of our discussion in the two divisions of this course.

\section{III}

The plan of the proposed investigation has now been set before you in outline. May I next undertake to indicate a little more precisely not merely what problems we are to attempt, but the sort of positive argument that we are to use, and the kind of result that we may hope to reach? A philosophy must indeed be judged not by its theses, but by its methods; and not upon the basis of mere summaries, but after a consideration of the details of its argument. Yet it helps to make clearer the way through an intricate realm of inquiry if one first surveys, as it were, from above, the country through which, in such an enterprise, the road is to pass. I propose then, to indicate at once, and in the rest of this lecture, where the central problem of the Theory of Being lies, and by what method I think that this problem is, in a general sense, to be solved. To state the proposed solution, however, even in the most abstract and necessarily uncon- 
vincing fashion, is to arouse comments as to the meaning of this thesis, as to its consequences, and, above all, in a discussion like the present, as to its bearing upon the more practical interests of religion. I think that we may be helped to an understanding hereafter, if I attempt at once to call out, and, by anticipation, to answer, a few such comments.

I am one of those who hold that when you ask the question: What is an Idea? and: How can Ideas stand in any true relation to Reality? you attack the world-knot in the way that promises most for the untying of its meshes. This way is, of course, very ancient. It is the way of Plato, and, in a sense, already the way of his Master. It is, in a different sense, the way of Kant. If you view philosophy in this fashion, you subordinate the study of the World as Fact to a reflection upon the World as Idea. Begin by accepting, upon faith and tradition, the mere brute Reality of the World as Fact, and there you are, sunk deep in an ocean of mysteries. The further you then proceed in the study of that world, the longer seems the way to God or to clearness, unless you from the start carry with you some sort of faith, perhaps a very blind and immediate faith, that God reigns, or that the facts in themselves are somehow clear. The World as Fact surprises you with all sorts of strange contracts. Now it reveals to you, in the mechanics and physics of the stars or in the processes of living beings, vast realms of marvellous reasonableness; now it bewilders you, in the endless diversities of natural facts, by a chaos of unintelligible fragments and of scattered events; now it lifts up your heart with wondrous glimpses of ineffable goodness; and now it arouses your wrath by frightful signs of cruelty and baseness. Conceive it as a realm for pure scientific theory; and, so far as your knowledge reaches, it is full at once of the show of a noble order, and of hints of a vain chance. On the other hand, conceive it as a realm of values, attempt to estimate its worth, and it baffles you with caprices, like a charming and yet hopelessly wayward child, or like a bad fairy. That is the world of brute natural fact as you, with your present form of consciousness, are forced to observe it, if you try to get any total impression of its behavior. And so, this World of Fact daily announces itself to you as a defiant mystery-a mystery such as Job faced, and such as the latest agnostic summary of empirical results, in their bearing upon our largest human interests, or such as even the latest pessimistic novel will no doubt any day present afresh to you, in all the ancient unkindliness that belongs to human fortune. 
The World as Fact is, then, for all of us, persistently baffling, unless we find somewhere else the key to it. The philosophers of the Platonic type have, however, long ago told us that this defect of our world of fact is due, at bottom, simply to the fault of our human type of consciousness. And hence a whole realm of philosophical inquiry has been devoted, in the best ages of speculative thinking, to a criticism of this human type of consciousness itself. Upon such a criticism, Plato founded his conception of the Ideal World. By such criticism, Plotinus sought to find the way upwards, through Soul to the realm of the Intellect, and beyond the Intellect to his Absolute "One." Through a similar criticism, Scholastic doctrine attempted to purify our human type of consciousness, until it should reach the realm of genuine spirituality, and attain an insight but a little lower than that of the conceived angelic type of intelligence. For all such thinkers, the raising of our type of consciousness to some higher level meant not only the winning of insight into Reality, but also the attainment of an inner and distinctly religious ideal. To a later and less technically pious form of thinking, one sees the transition in Spinoza, who was at once, as we now know, a child of Scholasticism, and a student of the more modern physical conceptions of his day,-at once a mystic, a realist, and a partisan of nature. For Spinoza too, it is our type of finite consciousness that makes our daily world of fact, or, as he prefers to say, of imagination, seem chaotic; and the way to truth still is to be found through an inner and reflective purification of experience. A widely different interpretation is given to the same fundamental conception, by Kant. But in Kant's case also, remote from his interests as is anything savoring of mysticism, the end of philosophical insight is again the vindication of a higher form of consciousness. For Kant, however, this is the consciousness of the Moral Reason, which recognizes no facts as worthy of its form of assurance, except the facts implied by the Good Will, and by the Law of the good will. All these ways then of asserting the primacy of the World as Idea over the World as Fact, agree in dealing with the problem of Reality from the side of the means through which we are supposed to be able to attain reality, that is, from the side of the Ideas.

\section{IV}

But if this is to be the general nature of our own inquiry also, then everything for us will depend upon the fundamental questions, al- 
ready stated, viz., first: What is an Idea? and second: How can an Idea be related to Reality? In the treatment of both these questions, however, various methods and theories at once come into sight. And, to begin with one of the favorite issues, namely the fundamental definition of the word "idea" itself, there is a well-known tendency in a good deal of philosophy, both ancient and modern, either to define an idea, as an Image, destined to picture facts external to the idea, or else, in some other way, to lay stress upon the externally cognitive or "representative" value of an idea as its immediately obvious and its most essential aspect. From this point of view, men have conceived that the power of ideas to know a Reality external to themselves, was indeed either something too obvious to excite inquiry, or else an ultimate and inexplicable power. "Ideas exist," says this view, "and they exist as knowing facts external to themselves. And this is their fundamental character." Now I myself shall, in these lectures, regard this power of ideas to cognize facts external to themselves not as a primal fact of existence but as an aspect of ideas which decidedly needs reflective consideration, and a very critical restatement. Hence I cannot here begin by saying: "Ideas are states of mind that image facts external to themselves." That would be useful enough as a definition of ideas in a Psychology of Cognition. For such a Psychology would presuppose what we are here critically to consider, namely, the very possibility of a cognition of Being. But, for the purpose of our present theory, the definition of the term "idea" must be made in such wise as not formally to presuppose the power of ideas to have cognitive relations to outer objects.

Moreover, in attempting a definition of the general term "idea," while I shall not be attempting a psychology of cognition, I shall myself be guided by certain psychological analyses of the mere contents of our consciousness,-analyses which have become prominent in recent discussion. What is often called the active and sometimes also the motor aspect of our mental life, has been much dwelt upon of late. This is no place, and at present we have no need, for a psychological theory of the origin or of the causes of what is called activity, but as a fact, you have in your mental life a sort of consciousness accompanying the processes by which, as the psychologists are accustomed to say, you adjust your organism to its environment; and this sort of consciousness differs, in some notable features, from what takes place in your mind in so far as the mere 
excitation of your sense organs by the outer world is regarded apart from the experiences that you have when you are said to react upon your impressions. The difference between merely seeing your friend, or hearing his voice, and consciously or actively regarding him as your friend, and behaving towards him in a friendly way, is a difference obvious to consciousness, whatever your theory of the sources of mental activity. Now this difference between outer sense impressions, or images derived from such impressions, and active responses to sense impression, or ideas founded upon such responses, is not merely a difference between what is sometimes called the intellect, and what is called the will. For, as a fact, the intellectual life is as much bound up with our consciousness of our acts as is the will. There is no purely intellectual life, just as there is no purely voluntary life. The difference between knowledge and will, so far as it has a metaphysical meaning, will concern us much later. For the present, it is enough to note that your intelligent ideas of things never consist of mere images of the things, but always involve a consciousness of how you propose to act towards the things of which you have ideas. A sword is an object that you would propose to use, or to regard in one way, while a pen is to be used in another; your idea of the object involves the memory of the appropriate act. Your idea of your friend differs from your idea of your enemy by virtue of your consciousness of your different attitude and intended behaviour towards these objects. Complex scientific ideas, viewed as to their conscious significance, are, as Professor Stout ${ }^{1}$ has well said, plans of action, ways of constructing the objects of your scientific consciousness. Intelligent ideas then, belong, so to speak, to the motor side of your life rather than to the merely sensory. This was what Kant meant by the spontaneity of the understanding. To be sure, a true scientific idea is a mental construction supposed to correspond with an outer object, or to imitate that object. But when we try to define the idea in itself, as a conscious fact, our best means is to lay stress upon the sort of will, or active meaning, which any idea involves for the mind that forms the idea.

By the word "Idea," then, as we shall use it when, after having criticised opposing theories, we come to state, in these lectures, our own thesis, I shall mean in the end any state of consciousness, whether simple or complex, which, when present, is then and there viewed as at least the partial expression or embodiment of a single

1 Stout, Analytic Psychology, Vol. II, Chap. VIII, especially pp. I14, I24. 
conscious purpose. I shall indeed say nothing for the present as to what causes an idea. But I shall assert that an idea appears in consciousness as having the significance of an act of will. I shall also dwell upon the inner purpose, and not upon the external relations, as the primary and essential feature of an idea. For instance, you sing to yourself a melody, you are then and there conscious that the melody as you hear yourself singing it, partially fulfils and embodies a purpose. Well, in this sense, your melody, at the moment when you sing it, or even when you silently listen to its imagined presence, constitutes a musical idea, and is often so called. You may so regard the melody without yet explicitly dwelling upon the externally cognitive value of the musical idea, as the representative of a melody sung or composed by somebody else. You may even suppose the melody original with yourself, unique, and sung now for the first time. Even so, it would remain just as truly a musical idea, however partial or fragmentary; for it would then and there, when sung, or even when inwardly heard, partly embody your own conscious purpose. In the same sense, any conscious act, at the moment when you perform it, not merely expresses, but is, in my present sense, an idea. To count ten is thus also an idea, if the counting fulfils and embodies, in however incomplete and fragmentary a way, your conscious purpose, and that quite apart from the fact that counting ten also may enable you to cognize the numerical character of facts external to the conscious idea of ten itself. In brief, an idea, in my present definition may, and, as a fact always does, if you please, appear to be representative of a fact existent beyond itself. But the primary character, which makes it an idea, is not this its representative character, is not its vicarious assumption of the responsibility of standing for a being beyond itself, but is its inner character as relatively fulfilling the purpose (that is, at presenting the partial fulfilment of the purpose), which is in the consciousness of the moment wherein the idea takes place. It is in this sense that we speak of any artistic idea, as present in the creative mind of the artist. I propose, in stating my own view hereafter, to use the word "idea" in this general sense.

Well, this definition of the primary character of an idea, enables me at once to deal with a conception which will play no small part in our later discussions. I refer to the very conception of the Meaning of an idea. One very fair way to define an idea, had we chosen to use that way, might have been to say: An Idea is any state of 
mind that has a conscious meaning. Thus, according to my present usage of the word "idea," a color, when merely seen, is in so far, for consciousness, no idea. A brute noise, merely heard, is no idea. But a melody, when sung, a picture, when in its wholeness actively appreciated, or the inner memory of your friend now in your mind, is an idea. For each of these latter states means something to you at the instant when you get it present to consciousness. But now, what is this meaning of any idea? What does one mean by a meaning? To this question, I give, for the instant, an intentionally partial answer. I have just said that an idea in any state of mind, or complex of states, that, when present, is consciously viewed as the relatively completed embodiment, and therefore already as the partial fulfilment of a purpose. Now this purpose, just in so far as it gets a present conscious embodiment in the contents and in the form of the complex state called the idea, constitutes what I shall hereafter call the Internal Meaning of the Idea. Or, to repeat, the state or complex of states called the idea, presents to consciousness the expressed although in general the incomplete fulfilment of a purpose. In presence of this fulfilment, one could, as it were, consciously say: "That is what I want, and just in so far I have it. The purpose of singing or of imagining the melody is what I want fulfilled; and, in this musical idea, I have it at least partially fulfilled." Well, this purpose, when viewed as fulfilled through the state called the idea, is the internal meaning of the idea. Or yet once more,-to distinguish our terms a little more sharply,-in advance of the presence of the idea in consciousness, one could abstractly speak of the purpose as somewhat not yet fulfilled. Hereupon let there come the idea as the complex of conscious states, the so-called act wherein this purpose gets, as it were, embodied, and relatively speaking, accomplished. Then, finally, we shall have the internal meaning of the idea, and this internal meaning of the completed idea is the purpose viewed as so far embodied in the idea, the soul, as it were, which the idea gives body. Any idea then, viewed as a collection of states, must have its internal meaning, since, being an idea, it does in some degree embody its purpose. And our two terms, "purpose embodied in the idea," and "internal meaning of the idea," represent the same subject-matter viewed in two aspects. The purpose which the idea, when it comes, is to fulfil, may first be viewed apart from the fulfilment. Then it remains, so far, mere purpose. Or it may be viewed as expressed and so far partially accomplished by means of the complex 
state called the idea, and then it is termed "the present internal meaning of this state."

\section{V}

So now we have defined what we mean by an idea, and what we mean by the internal meaning of an idea. But ideas often seem to have a meaning, yes, as one must add, finite ideas always undertake or appear to have a meaning, that is not exhausted by this conscious internal meaning presented and relatively fulfilled at the moment when the idea is there for our finite view. The melody sung, the artist's idea, the thought of your absent friend-a thought on which you love to dwell: all these not merely have their obvious internal meaning, as meeting a conscious purpose by their very presence, but also they at least appear to have that other sort of meaning, that reference beyond themselves to objects, that cognitive relation to outer facts, that attempted correspondence with outer facts, which many accounts of our ideas regard as their primary, inexplicable, and ultimate character. I call this second, and, for me, still problematic and derived aspect of the nature of ideas, their apparently External Meaning. In this sense it is that I say, "The melody sung by me not only is an idea internally meaning the embodiment of my purpose at the instant when I sing it, but also is an idea that means, and that in this sense externally means, the object called, say, a certain theme which Beethoven composed." In this same sense, your idea of your absent friend, is, for my definition, an idea primarily, because you now fulfil some of your love for dwelling upon your inner affection for your friend by getting the idea present to mind. But you also regard it as an idea which, in the external sense, is said to mean the real being called your friend, in so far as the idea is said to refer to that real friend, and to resemble him. This external meaning, I say, appears to be very different from the internal meaning, and wholly to transcend the latter.

By thus first distinguishing sharply between the conscious internal meaning of an idea and its apparently external meaning, we get before us an important way of stating the problem of knowledge or, in other words, the problem of the whole relation between Idea and Being. We shall find this not only a very general, but a very fundamental, and, as I believe, despite numerous philosophical discussions, still a comparatively neglected way. And in problems 
of this kind so much turns upon the statement of the issue, that I must be excused for thus dwelling at length, at this early stage, upon the precise sense in which we are to employ our terms.

Plainly, then, whoever studies either a special science, or a problem of general metaphysics, is indeed concerned with what he then and there views as the external meaning of certain ideas. And an idea, when thus viewed, appears as if it were essentially a sort of imitation or image of a being, and this being, the external object of our thoughtful imitation, appears to be, in so far, quite separate from these our ideas that imitate its characters or that attempt to correspond to them. From such a point of view, our ideas seemed destined to perform a task which is externally set for them by the real world. I count, but I count, in ordinary life, what I take to be real objects, existent quite apart from my counting. Suppose that I count ships seen from the shore. There, says common sense, are the ships, sailing by themselves, and quite indifferent to whether anybody counts them or not. In advance of the counting, the ships, in so far as they are a real collection, have their number. This common sense also presupposes. Let there be seen, yonder, on the sea, nine ships or ten; this number of the real ships is in itself determinate. It does not result from my counting, but is the standard for the latter to follow. The numerical ideas of anybody who counts the ships must either repeat the preëxistent facts, or else fail to report those facts accurately. That alternative seems absolute and final. The question how anybody ever comes to count ships at all, is a question for psychology. But there remains for the seeker after metaphysical truth, just as much as for the man of common sense, the apparently sharp alternative: Either actual ships, whose multitude is just what it happens to be, whose number preëxists, in advance of any counting, are correctly represented by the ideas of one who happens to be able to count, or else these ships are incorrectly counted. In the latter case we seem to be forced to say that the counting process misses its external aim. In the former case we say that the ideas expressed by the one who counts are true. But in both cases alike the ideas in question thus appear to be true or false by virtue of their external meaning, by virtue of the fact that they either correspond or do not correspond to facts which are themselves no part of the ideas. This simple instance of the ships and of the ideas of a man who sits watching and counting the ships, is obviously typical of all instances of the familiar relation of ideas 
to Being, as the metaphysics of common sense views Being, or of the relation of ideas to what we have here called the objects of their external meaning. That ideas have such external meanings, that they do refer to facts existent wholly apart from themselves, that their relation to these facts is one of successful correspondence or of error-producing non-correspondence, that the ideas in so far aim, not merely to embody, like the musical ideas just exemplified, an internal purpose, but also to imitate, in the form of their conscious structure and in the relationship of their own elements, the structure and relationship of a world of independent facts,-what could possibly seem, from such a common-sense point of view, more obvious than all this? And if common sense presupposes that ideas have such external meanings, how much more does not natural science appear to involve the recognition of this essentially imitative function of ideas?

In any special natural science, a scientific description appears as an adjustment, express, conscious, exact, of the internal structure of a system of ideas to the external structure of a world of preëxistent facts; and the business of science has been repeatedly defined, of late years, as simply and wholly taken up with the exact description of the facts of nature. Now the world of Being, when viewed in this light, appears to mean simply the same as the fact world, the external object of our ideas, the object that ideas must imitate, whatever their internal purpose, unless they want to be false. But for this very reason, no study of the inner structure of ideas, of their conscious conformity to their internal purpose, can so far promise to throw any direct light upon their success in fulfilling their external purpose. Or, as people usually say, you cannot make out the truth about facts by studying your "mere ideas." And so, as people constantly insist, no devotion to the elaboration of the internal meaning of your own ideas can get you in presence of the truth about Being. The world of Being is whatever it happens to be, as the collection of ships is what it is, before you count. Internal purposes cannot predetermine external conformity to truth. You cannot evolve facts out of your inner consciousness. Ideas about Being are not to be justified like melodies, by their internal conformity to the purpose of the moment when they consciously live. They must submit to standards that they themselves in no sense create. Such is the burden of common sense, and of special science, when they tell us about this aspect of the meaning of our ideas. 
I state thus explicitly a very familiar view as to the whole externally cognitive function and value of ideas. I mean thus to emphasize the primary appearance of hopeless contrast between the internal purpose and the external validity of ideas. In fact, nothing could seem sharper than the contrast thus indicated between the melody on the one hand, the musical idea, as it comes to mind and is enjoyed for its beauty while it passes before consciousness, and the counting of the ships, on the other hand,-a process whose whole success depends upon its conformity to what seem to be absolutely indifferent and independent outer facts. In the one case we have the embodiment of a conscious inner purpose,-a purpose which is won through the very act of the moment, and by virtue of the mere presence of a certain series of mental contents. In the other case we have a conformity to outer truth,-a conformity that no inner clearness, no well-wrought network of cunning ideal contrivance, can secure, unless the idea first submits to the authority of external existence.

And yet, sharp as is this apparent contrast, every student of philosophy knows how profound are also the motives that have led some philosophers to doubt whether such contrast can really be as ultimate as it seems. After all, the counting of the ships is valid or invalid not alone because of the supposed independent being of the ships, but also because of the conscious act whereby just this collection of ships was first consciously selected for counting. After all, then, no idea is true or is false except with reference to the object that this very idea first means to select as its own object. Apart from what the idea itself thus somehow assigns as its own task, even that independent being yonder, if you assume such being, cannot determine the success or failure of the idea. It is the idea then that first says: "I mean this or that object. That is for my object. Of that I am thinking. To that I want to conform." And apart from such conscious selection, apart from such ideal predetermination of the object on the part of the idea, apart from such free voluntary submission of the idea to its self-imposed task, the object itself, the fact world, in its independence, can do nothing either to confirm or refute the idea. Now in this extremely elementary consideration, namely, in the consideration that unless ideas first voluntarily bind themselves to a given task, and so, by their internal purpose, already commit themselves to a certain selection of its object, they are neither true nor false,-in this con- 
sideration, I say, there may be hidden consequences that we shall later find momentous for the whole theory of Being and of truth. This consideration, that despite the seemingly hopeless contrast between internal and external meaning, ideas really possess truth or falsity only by virtue of their own selection of their task as ideas, is essentially the same as the consideration that led Kant to regard the understanding as the creator of the phenomenal nature over which science gradually wins conscious control, and that led Hegel to call the world the embodied Idea. This consideration, then, is not novel, but I believe it to be fundamental and of inexhaustible importance. I believe also that some of its aspects are still far too much neglected. And I propose to devote these lectures to its elaboration, and to a study of its relations to the various conceptions of Reality which have determined the scientific and religious life of humanity.

In any case I say, then, at the outset, that the whole problem of the nature of Being will for us, in the end, reduce to the question: How is the internal meaning of ideas consistent with their apparently external meaning? Or again: How is it possible that an idea, which is an idea essentially and primarily because of the inner purpose that it consciously fulfils by its presence, also possesses a meaning that in any sense appears to go beyond this internal purpose? We shall, in dealing with this problem, first find, by a development of the consideration just barely indicated, that the external meaning must itself be interpreted, not primarily in the sense of mere dependence upon the brute facts, but in terms of the inner purpose of the idea itself. We shall, perhaps to our surprise, reach the seemingly paradoxical and essentially idealistic thesis that no being in heaven or in earth, or in the waters under the earth, has power to give to an idea any purpose unless, the idea itself, as idea, as a fragment of life, as a conscious thrill, so to speak, of inner meaning, first somehow truly learns so to develope its internal meaning as to assign to itself just that specific purpose. In other words, we shall find that while, for our purposes, we, the critics, must first sharply distinguish the apparently external purpose that, as it were, from without, we assign to the idea, from the internal meaning of the idea, as present to a passing conscious instant, still, this our assignment of the external purpose, this our assertion that the idea knows or resembles, or imitates, or corresponds to, fact wholly beyond itself, must in the end be justified, if at all, by appeal to 
the truth, i.e. to the adequate expression and development of the internal meaning of the idea itself. In other words, we shall find either that the external meaning is genuinely continuous with the internal meaning, and is inwardly involved in the latter, or else that the idea has no external meaning at all. In brief, our abstract sundering of the apparently external from the consciously internal meaning of the idea must be first made very sharp, as we have just deliberately made it, only in order that later, when we learn the true relations, we may come to see the genuine and final unity of internal and external meaning. Our first definition of the idea seems to make, yes, in its abstract statement deliberately tries to make, as you see, the external meaning something sharply contrasted with the internal meaning. Our final result will simply reabsorb the secondary aspect, the external meaning, into the completed primary aspect,-the completely embodied internal meaning of the idea. We shall assert, in the end, that the final meaning of every complete idea, when fully developed, must be viewed as wholly an internal meaning, and that all apparently external meanings become consistent with internal meanings only by virtue of thus coming to be viewed as aspects of the true internal meaning.

To illustrate this thesis by the cases already used: The melody sung or internally but voluntarily heard, in the moment of memory, is, for the singer's or hearer's consciousness, a musical idea. It has so far its internal meaning. And to say so much first means simply that to the singer, as he sings, or to the silent memory of a musical imagination, the present melody imperfectly and partially fulfils a conscious purpose, the purpose of the flying moment. On the other hand, the melody may be viewed by a critic as an idea corresponding to external facts. The singer or hearer too may himself say as he sings or remembers: "This is the song my beloved sang," or "This is the theme that Beethoven composed in his Fidelio." In such a case, the idea is said to have its apparently external meaning, and this, its reference to facts not now and here given, is the idea's general relation to what we call true Being. And such reference not only seems at first very sharply different from the internal meaning, but must, for our purposes, at first be sundered by definition from that internal meaning even more sharply than common sense distinguishes the two. For abstract sundering is, in us mortals, the necessary preliminary to grasping the unity of truth. The internal meaning is a purpose present in the passing 
moment, but here imperfectly embodied. Common sense calls it, as such, an expression of transient living intent, an affair of Will. Psychology explains the presence and the partial present efficacy of this purpose by the laws of motor processes, of Habit, or of what is often called association. Ethical doctrine finds in such winning of inner purposes the region where Conscience itself, and the pure moral Intention, are most concerned. On the other hand, the apparently external meaning of the idea is at first said to be an affair of the externally cognitive intellect, and of the hard facts of an independently real world. Not purpose, but the unchangeable laws of the Reality, not the inner life, but the Universe, thus at first seems from without to assign to the idea whatever external meaning it is to obtain. Subject and Object are here supposed to meet,to meet in this fact that ideas have their external meaning,- but to meet as foreign powers.

Now we are first to recognize, even more clearly, I say, than common sense, the sharpness of this apparent antithesis between the conscious internal and the seemingly external meaning. Here, as I have said, is indeed the world-knot. We are to recognize the problem, but we are, nevertheless, to answer it in the end (when we get behind the appearances, and supplement the abstractions), by the thesis that at bottom, the external meaning is only apparently external, and, in very truth, is but an aspect of the completely developed internal meaning. We are to assert that just what the internal meaning already imperfectly but consciously is, namely, purpose relatively fulfilled, just that, and nothing else, the apparently external meaning when truly comprehended also proves to be, namely, the entire expression of the very Will that is fragmentarily embodied in the life of the flying conscious idea,-the fulfilment of the very aim that is hinted in the instant. Or, in other words, we are to assert that, in the case mentioned, the artist who composed, the beloved who sang the melody, are in verity present, as truly implied aspects of meaning, and as fulfilling a purpose, in the completely developed internal meaning of the very idea that now, in its finitude, seems to view them merely as absent. I deliberately choose, in this way, a paradoxical illustration. The argument must hereafter justify the thesis. I can here only indicate what we hereafter propose to develope as our theory of the true relation of Idea and Being. It will also be a theory, as you see, of the unity of the whole very World Life itself. 
In brief, by considerations of this type, we propose to answer the question: What is to be? by the assertion that: To be means simply to express, to embody the complete internal meaning of a certain absolute system of ideas,-a system, moreover, which is genuinely implied in the true internal meaning or purpose of every finite idea, however fragmentary.

\section{VI}

You may observe already, even in this wholly preliminary sketch of the particular form of Idealism to be developed in these lectures, two principal features. First, Our account of the nature of Being, and of the relation between Idea and Being, is to be founded explicitly upon a theory of the way in which ideas possess their own meaning. Secondly, Our theory of the nature of Meaning is to be founded upon a definition in terms of Will and Purpose. We do not indeed say, Our will causes our ideas. But we do say, Our ideas now imperfectly embody our will. And the real world is just our whole will embodied.

I may add, at once, two further remarks concerning the more technical aspects of the argument by which we shall develope our thesis. The first remark is, that the process by which we shall pass from a study of the first or fragmentary internal meaning of finite ideas to that conception of their completed internal meaning in terms of which our theory of Being is to be defined, is a process analogous to that by which modern mathematical speculation has undertaken to deal with its own concepts of the type called by the Germans Grenzbegriffe, or Limiting Concepts, or better, Concepts of Limits. As a fact, one of the first things to be noted about our conception of Being is that, as a matter of Logic, it is the concept of a limit, namely of that limit to which the internal meaning or purpose of an idea tends as it grows consciously determinate. Our Being resembles the concept of the so-called irrational numbers. Somewhat as they are related to the various so-called "fundamental series" of rational numbers, somewhat in that way is Being related to the various thinking processes that approach it, as it were, from without, and undertake to define it as at once their external meaning, and their unattainable goal. That which is, is for thought, at once the fulfilment and the limit of the thinking process. The thinking process itself is a process whereby at once meanings tend to 
become determinate, and external objects tend to become internal meanings. Let my process of determining my own internal meaning simply proceed to its own limit, and then I shall face Being. I shall not only imitate my object as another, and correspond to it from without: I shall become one with it, and so internally possess it. This is a very technical statement of our present thesis, and of our form of Idealism,-a statement which only our later study can justify. But in making that statement here, I merely call attention to the fact that the process of defining limits is one which mathematical science has not only developed, but in large measure, at the present time, prepared for philosophical adaptation, so that to view the concept of Being in this light is to approach it with an interest for which recent research has decidedly smoothed the way. We shall meet both with false ways of defining the limit, and with true ways.

My second remark is closely related to the first, but is somewhat less technical, and involves a return to the practical aspects of our intended theory. I have just said that the development of the conception of an idea whose internal meaning is fully completed, and whose relation to Being is even thereby defined, will involve a discussion of the way in which our internal, our fragmentary finite meanings, as they appear in our flying moments, are to attain a determined character or are to become, as Hegel would say, bestimmt, so as to pass from vagueness to precision. Our theory, as you already see, will identify finite ignorance of Realty with finite vagueness of meaning, will assert that the very Absolute, in all its fulness of life, is even now the object that you really mean by your fragmentary passing ideas, and that the defect of your present human form of momentary consciousness lies in the fact that you just now do not know precisely what you mean. Increase of knowledge, therefore, would really involve increase of determination in your present meaning. The universe you have always with you, as your true internal meaning. Only this, your meaning, you now, in view of the defect of your momentary form of consciousness, realize vaguely, abstractly, without determination. And, as we have further asserted, this indetermination of your ideas also involves a hesitant indeterminateness of your momentary will, a vagueness of conscious ideal as well as of idea, a failure not only to possess, but wholly to know what you want. To pass to your real and completed meaning, to the meaning implied in this very 
moment's vagueness, would be a passage to absolute determinateness. So to pass would therefore be to know with full determination truths of an often desired type, truths such as: What you yourself are; and, who you are, as this individual; what this individual physical fact now before you is. Yes, it would be to know what the whole individual Being called the World is; and who the Individual of Individuals, namely the Absolute, or God himself, is. Just such final determinateness, just such precision, definiteness, finality of meaning, constitutes that limit of your own internal meaning which our theory will hereafter seek to characterize. And so my present remark hereupon is that, in following our enterprise of defining Being, we shall not be looking for mere abstract principles, but we shall be seeking for the most concrete objects in the world, namely for Individual Beings, and for the system that links them in one Individual Whole,-for Individuals viewed as the limits towards which all ideas of universal meanings tend, and for the Absolute as himself simply the highest fulfilment of the very category of Individuality, the Individual of Individuals.

Will, meaning, individuality, these will prove to be the constant accompaniments and the outcome of our whole theory of ideas, of thought, and of being. And in the light of these remarks we may now be able to anticipate more precisely the form of doctrine to which these lectures are to be devoted.

Idealism in some sense is indeed familiar in modern doctrine. And familiar also to readers of idealistic literature is some such assertion, as that the whole of Reality is the expression of a single system of thought, the fulfilment of a single conscious Purpose, or the realm of one internally harmonized Experience. But what the interested learners ask of idealistic teachers to-day is, as you are all aware, a more explicit statement as to just how Thought and Purpose, Idea and Will, and above all finite thought and will, and absolute thought and will, are, by any idealist, to be conceived as related to each other. My definitions in the foregoing have been deliberately intended to prepare the way for our later direct dealing with just these issues. An idea, in the present discussion, is first of all to be defined in terms of the internal purpose, or, if you choose, in terms of the Will, that it expresses consciously, if imperfectly, at the instant when it comes to mind. Its external meaning, its externally cognitive function as a knower of outer Reality, is thus in these lectures to be treated as explicitly secondary to this its 
internal value, this its character as meaning the conscious fulfilment of an end, the conscious expression of an interest, of a desire, of a volition. To be sure, thus to define, as we shall see, is not to separate knowing from willing, but it is rather to lay stress, from the outset, upon the unity of knowledge and will, first in our finite consciousness, and later, as we shall see, in the Absolute. Our present statement of our doctrine is therefore not to be accused, at any point, of neglecting the aspect of value, the teleological, the volitional aspect, which consciousness everywhere possesses. We shall reach indeed in the end the conception of an Absolute Thought, but this conception will be in explicit unity with the conception of an Absolute Purpose. Furthermore, as we have just asserted, we shall find that the defect of our momentary internal purposes, as they come to our passing consciousness, is that they imply an individuality, both in ourselves and in our facts of experience, which we do not wholly get presented to ourselves at any one instant. Or in other words, we finite beings live in the search for individuality, of life, of will, of experience, in brief, of meaning. The whole meaning, which is the world, the Reality, will prove to be, for this very reason, not a barren Absolute, which devours individuals, not a wilderness such as Meister Eckhart found in God, a Stille Wüste, da Nieman heime ist, a place where there is no definite life, nor yet a whole that absorbs definition, but a whole that is just to the finite aspect of every flying moment, and of every transient or permanent form of finite selfhood,-a whole that is an individual system of rationally linked and determinate, but for that very reason not externally determined, ethically free individuals, who are nevertheless One in God. It is just because all meanings, in the end, will prove to be internal meanings, that this which the internal meaning most loves, namely the presence of concrete fulfilment, of life, of pulsating and originative will, of freedom, and of individuality, will prove, for our view, to be of the very essence of the Absolute Meaning of the world. This, I say, will prove to be the sense of our central thesis; and here will be a contrast between our form of Idealism and some other forms.

And thus, in this wholly preliminary statement, I have outlined our task, have indicated its relation to the problems of religion, have suggested its historical affiliations, and have, in a measure, predicted its course. I have defined in general the problem of the 
relation of the World as Idea to the World as Fact, and have stated our issue as precisely this relation between Ideas and Reality. In order to assist in clarifying our undertaking, I have also given a general definition of what an idea is, and have stated the logical contrast between the consciously internal and the apparently external meaning of any finite idea. And finally I have asserted that, in dealing with the problem as to how internal and external meaning can be reduced to a consistent whole, we shall be especially guided to fruitful reflection upon the final relation of the World and the Individual. This, then, is our programme. The rest must be the actual task.

I am not unaware how valueless, in philosophy, are mere promises. All, in this field, must turn upon the method of work. The question in philosophy is not about the interest or the hopefulness of your creed, but about your rational grounds for holding your convictions. I accept the decidedly strict limitations imposed by this consideration, and shall try, when we come to the heart of our critical and constructive task, to be as explicit as the allotted time permits, both in expounding the precise sense of the doctrine now loosely and dogmatically sketched in the foregoing statement, and in explaining the grounds that lead me to prefer it, as a solution both of logical and of empirical problems, to its rivals. But the way of detailed argument is long, and the outlook of the whole enterprise may often seem, as we proceed with our difficulties, dark and perplexing. Introductions also have their rights; and I have meant in these opening words merely to recount the dream of which what follows must furnish both the interpretation and, in a measure, the justification. 
